\title{
Dielectric Breakdown of Epoxy-Based Composites: Relative Influence of Physical and Chemical Aging
}

\author{
L. Vouyovitch, N.D. Alberola, L. Flandin \\ LMOPS - UMR 5041 - CNRS Université de Savoie \\ Bat IUT Savoie Technolac \\ 73376 LE Bourget Du Lac Cedex, France
}

\author{
A. Beroual \\ CEGELY, Ecole Centrale de Lyon \\ 36 avenue Guy de Collongue \\ 69134 Ecully Cedex, France \\ and J-L. Bessede \\ AREVA T\&D, ARC \\ 130 rue Léon Blum \\ 69621 Villeurbanne Cedex France
}

\begin{abstract}
The effect of aging on the dielectric strength of epoxy-inorganic particle composites used for insulators in the high voltage industry is reported. A Differential Scanning Calorimetry analysis of an insulator aged twenty years in actual service conditions indicated both a chemical degradation and a structural recovery of the polymer network. This composite exhibited however a breakdown field comparable to that of a fresh sample with the same formulation. An accelerated physical aging was thus performed which lead to a large increase in the high voltage performance of the newly processes composite over time. This improvement was attributed to a densification of the thermoset resin, which impeded tree growth. It was also observed that the choice of the electrode geometry greatly alters the measurements under high electric field. In a quasi-homogeneous field configuration, the breakdown was mainly governed by the major flaws at the sample scale, namely the reinforcing particles. On the contrary, under a divergent field (with a point - plane electrode arrangement), the field was essentially localized at the point electrode tip, and the major flaws might not be reachable by the damage tree. It hence appeared that the measurements performed in a quasi-homogeneous field are not very sensitive to the variations within the polymeric matrix as are the measurements under a divergent field.
\end{abstract}

Index Terms - Epoxy resins, aging, inhomogeneous media, dielectric breakdown, divergent, quasi-homogeneous, DSC, physical aging, insulators.

\section{INTRODUCTION}

The safe operation of high voltage electrical energy transmission grids depends on the reliability of its components, as switchgears, power transformers and gas insulating lines. Their reliability depends primarily on the performance of the insulating structures they contain. At present time, due to the reduction of dimensions of the equipment and thenceforth to

Manuscript received on 11 May 2005, in final form 16 November 2005. such the increase of the heat density to be evacuated, the insulating materials should have the best possible initial properties including a high dielectric strength and required thermo-mechanical properties.

These properties should limit some short-term breakdown mechanisms, distinguished in three main types:

(i) Electrical breakdown: this is a very fast mechanism which is not preceded by any increase of the temperature [1]. The changing in the structure results directly from the action of 
the constraints due to the electric field. Two theories have been proposed to explain the electrical breakdown. The first one (called "intrinsic breakdown") considers that the breakdown occurs when instability of the electronic current appears in the dielectric [1-3]. According to the second theory (called "breakdown by avalanches"), the breakdown criterion is assumed to be the electric field for which the electronic multiplication process reach inadmissible proportions. The material ceases to be a dielectric and then, it becomes conducting.

(ii) Thermal breakdown: it is due to a thermal imbalance. It is connected with the energetic losses resulting from the mobility of the polar systems [1, 4-5]. When an electric field is applied, the existence of charge carriers in the insulating material induces the appearance of a conducting current which can lead to the heating of this insulator by Joule effect. However, this current is not the unique source of the heat. Indeed, relaxation phenomena which are present in dielectrics, when submitted to an alternative field, can also engender losses which contribute in their turn to the heating. If the heat is not evacuated as fast as it is produced, the temperature in the insulating sample increases, with the time, with a velocity more or less important, depending on the amplitude of the applied voltage. And when the heat produced in the dielectric is higher than that evacuated, then an instability appears. The increase of the temperature induces structural changing and the destruction of the dielectric.

(iii) Electromechanical breakdown: it results from the conjugation of two types of constraints: electric and mechanics. It depends mainly on the mechanical characteristics of the sample. Indeed, when the material is submitted to an electrical field, the electrostatic pressure due to the mutual attractions between the electrodes can reduce its thickness by a mechanical deformation [6-7]. If this electrostatic pressure is sufficient to produce a considerable deformation, the electrical field will be reinforced. It results a reduction of the dielectric strength and thence the breakdown of the material occurs.

Among the insulating materials, epoxy based composites [1] are widely used for these very demanding applications because of their ability to withstand high electric fields, which limits short-terms breakdown. Nevertheless, the resulting multiple stresses (electrical [8], mechanical and thermal but also environmental) in operating conditions might result in large modifications over time [1,9-18] and thenceforth to the deterioration of the composite structure at long time.

This later might lead to the initiation of partial discharges and electrical trees resulting in the breakdown of the insulator. The partial discharges result of local enhancements of the electrical field within the inclusions or gaseous cavities which can be present in the material. They appear when the applied voltage reaches a threshold value corresponding to the Paschen minimum of the gas in presence (air or others). Their action can lead to chemical and radical transformations (i.e. scission of the molecular bonds under the electronic and ionic bombardment, local heating or creation of radicals) leading to the failure of the material in consequence of mechanisms such as the propagation through the material of microscopic channels, the cumulative heating due to the discharges. The partial discharges lead to the initiation of electrical treeing. Each irregularity (protrusion) at the insulating wall (interface) of a cavity (void) favors the fast propagation of treeing and lead to the breakdown. Also, Loffelmacher [19], in 1976, linked the partial discharges to the electrical breakdown of epoxy composites. In this description of the electrical tree growing, the initiation is done in front of the needle electrode by partial discharges, leading to the creation of a channel. The gaseous decomposition products of the destroyed material raise the pressure and the density of the channel. It was noticed that the gas pressure in the partial discharges channel can exceed $1.2 \times 10^{7} \mathrm{~Pa}(120$ bars $)$. Then the combination of electrical and thermo-mechanical stresses allows the tree to grow up to breakdown.

It is then of a major interest to understand and to predict the structural changes of these kinds of materials when submitted to tough conditions for long periods of time and, more specifically, the influence of these changes on the dielectric strength.

In operating conditions, because of the low thermal conductivity of polymer network in epoxy based composites, the application of high electric field induces temperature overshoots leading to thermal aging $[1,20]$. Two cases have to be considered depending on the temperature reached:

If the temperature $\mathrm{T}$ remains below the glass transition temperature $\mathrm{Tg}(\mathrm{T}<\mathrm{Tg})$ over a long time, the so-called physical aging of the amorphous phase occurs, resulting in a densification of the polymer network [21]. Beyer et al [22] and then Dissado et al [1] suggested that this phenomenon could also be induced by the electric field.

o If the temperature goes beyond the $\mathrm{Tg}$ of polymer, chemical degradations such as chains scissions, formations of radicals and polar groups, recombination of chain segments [910, 12-13] will most likely happen within the polymeric network. Under electric field, these free radicals or dipoles could induce both (i) a conduction current leading to further overheating of the insulator by Joule effect. The insulator could this way, following a cumulative process, reach critical temperatures locally and prematurely undergo breakdown by the thermal mechanism [1]. A gradual ionization (ii) of the material could also occur, accelerated by ions resulting from the degradation and leading to breakdown by an avalanche mechanism [1].

It is worth noticing that "rejuvenated" samples reefers to sample that first underwent a physical ageing before being heated above the glass transition temperature. The latter treatment permits the polymer to reorganize back to a thermodynamic equilibrium. In particular an aged sample rejuvenates during the first DSC ramp and no physical ageing can be observed during the course of a second heating ramp. 
Few investigations have been reported on the influence of the physical ageing on the breakdown field or dielectric endurance of composites. Under high electric field, Dissado [1] mentioned that the increase in local density accompanying the physical aging could lead to strains generated formation of micro-voids that should act as flaws. This author forecasted that the physical aging could hence facilitate the electrical degradations in the form of partial discharges similar in nature to those observed in semi-crystalline polyethylene. On the contrary, Champion and Dodd [16] have studied the effect of this physical aging on the tree growth of unfilled epoxy anhydride networks. These authors have, in particular, established that the fractal dimension of trees increased with the materials age. For a large variation in aging times, they even observed a transition from filamentary-like to a bush-like structure of the damage tree. The authors concluded that the density increase associated with a reduction of internal stresses during the structural-aging process modified the electrical properties of epoxy networks. Such an interpretation has been confirmed by Auckland et al [23].

Thus, in actual service conditions, insulators undergo various stresses leading to chemical and physical microstructure changes susceptible to significantly transform their properties under high electric field.

This paper constitutes a contribution to the description and understanding of the relative contribution of the microstructural modifications induced by the physical aging of epoxy composites on the electrical breakdown strength.

For that purpose, an insulator-insulator composite based on an epoxy matrix and aged for 20 years in service was considered. The global impact of both physical aging and chemical modifications induced by the various stresses endured by the material over a long time were characterized. Then, laboratory aging was performed on the material and the dielectric strength was measured.

Finally, the relative contribution of the physical aging on the loss of breakdown strength of the epoxy is determined through comparison between physically-aged samples in laboratory and the operating-conditions aged sample.

\section{EXPERIMENTAL}

\subsection{DSC MEASUREMENTS}

Differential Scanning Calorimetry (DSC) analysis was carried out by using a DSC 7 Perkin Elmer device. The calorimeter had previously been calibrated with the indium standard. The analysis was then carried out with samples containing $10 \pm 1 \mathrm{mg}$ of polymer. Thermograms were recorded under nitrogen atmosphere from $40^{\circ} \mathrm{C}$ to $170^{\circ} \mathrm{C}$. Heat flows were measured at a heating rate of $10^{\circ} \mathrm{C} \cdot \mathrm{min}^{-1}$. For each sample, two successive heating runs were carried out with a 5 minutes hold stage at $170^{\circ} \mathrm{C}$ between each scan in order to erase the previous thermal history. From the thermogram recorded on the first heating run, the enthalpy excess related to the magnitude of the previous physical aging was determined.
A second heating run was performed at a heating rate of $10^{\circ} \mathrm{C} \cdot \mathrm{min}^{-1}$, in order to verify that the first heating run followed by the hold stage at $170^{\circ} \mathrm{C}$ did not induce some chemical degradations. The DSC experiments were carried out twice on each sample $(\mathrm{n}=2)$. In this paper $\mathrm{Tg}$ is taken as the onset value at which the thermogram splits from the base line.

\subsection{COMPOSITES AGED IN SERVICE}

Another composite formulated like C1 (see Table 1) was supplied by AREVA T\&D. The latter was taken back from service after twenty (20) years on site. This insulator, reference to as $\mathrm{C}^{*}$, was aged (i) in inert atmosphere, as air is excluded from the application, (ii) in a relatively low electric field of few $\mathrm{kV} / \mathrm{mm}$, (iii) in a range of temperatures that should remain below $85^{\circ} \mathrm{C}$.

A comparison of the physicochemical characteristics of the $\mathrm{C} 1$ and $\mathrm{C}^{*}$ materials was detailed else where [24]. In summary (Figure 1) the comparison of the DSC (Differential Scanning Calorimetry) thermograms for as-received and aged materials indicated:

$\mathrm{o}$ a large endothermic peak related to the physical aging of the $\mathrm{C} 1 *$ matrix,

o low $\mathrm{Tg}$ revealing that the polymeric matrix of $\mathrm{C} 1$ * underwent chemical degradations.

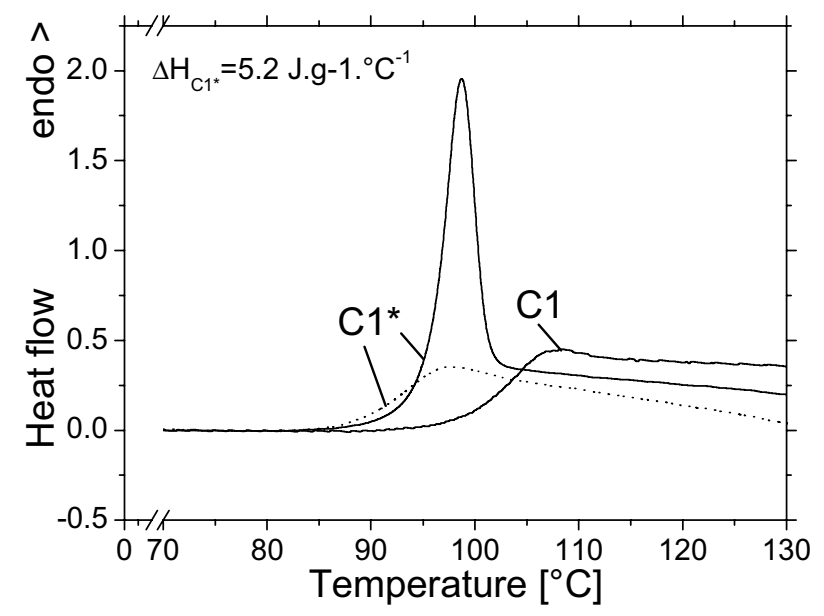

Figure 1. DSC thermograms of as-received composite $\mathrm{C} 1$ and 20-years-aged $\mathrm{C} 1{ }^{*}$ - first (solid lines) and second (dashed line) ramp of temperature.

The 20 years aged material $\left(\mathrm{C}^{*}\right)$ accordingly experienced structural modifications related to physical aging but also chemical degradations.

\subsection{AS-RECEIVED COMPOSITES}

The pre-polymer considered in this study was a DiGlycidyl Ether of Bisphenol A (DGEBA); it was combined to an anhydride hardener following the stoichiometry recommended by the supplier. Two systems of particle-filled composites were investigated (Table 1). The dc conductivity of the filler is an order of magnitude higher than that of the matrix [29]. 
Table 1. Main characteristics of the composites.

\begin{tabular}{llcc} 
& & C1 and C1* & C2 \\
\cline { 3 - 4 } Polymer & & Matrix M1 & Matrix \\
& & & M2 \\
\hline \multirow{2}{*}{ Filler } & Granulometry & $2-40 \mu \mathrm{m}$ & $3-30 \mu \mathrm{m}$ \\
& D50 & $6 \mu \mathrm{m}$ & $6.6 \mu \mathrm{m}$ \\
& Graded shape & lengthened & irregular \\
& $\% \mathrm{w}$. & $58 \pm 0.5$ & $67 \pm 0.5$ \\
\hline
\end{tabular}

The so-called $\mathrm{C} 1$ material is reinforced by $58.0 \pm 0.5 \mathrm{w} \%$ of mineral particles. The $\mathrm{C} 2$ material was processed with $67.0 \pm$ $0.5 \mathrm{w} \%$ of another type of mineral fillers, different in shape but similar in chemical nature (the exact chemical nature of which may not be disclosed). 2D observations of the composite with an optical microscope suggested that the amount of filler remained below the percolation threshold [29]. It is worth noticing that the chemical natures of the two matrices were slightly different, leading to slightly different $\mathrm{Tg}$. Before ageing the $\mathrm{Tg}$ for $\mathrm{C} 1$ and $\mathrm{C} 2$ were measured, close to 90 and $100^{\circ} \mathrm{C}$, respectively [24].

Despite their different components (resin, hardener and fillers), both systems were basically processed the same way. Prior to processing, the inorganic fillers were dried by placing them in an oven at $60^{\circ} \mathrm{C}$ for $48 \mathrm{~h}$ to reduce as much as possible the influence of water. The resin, the hardener and inorganic materials were then mixed and stirred at $56^{\circ} \mathrm{C}$ and degasified under vacuum. The mixture was then injected under pressure at the bottom of a vertical mould and underwent the cure process at $140^{\circ} \mathrm{C}$ for 15 minutes for both composites $\mathrm{C} 1$ and $\mathrm{C} 2$. These composites were then post cured $8 \mathrm{~h}$ at $140^{\circ} \mathrm{C}$ and $12 \mathrm{~h}$ at $60^{\circ} \mathrm{C}$ in order to fulfill the cross-linking reaction.

For fresh materials ( $\mathrm{C} 1$ and $\mathrm{C} 2)$ a physical aging in laboratory was carried out. The aging temperature was chosen to be $\operatorname{Tg}-18^{\circ} \mathrm{C}$ [21] in order to induce significant and maximum structural effects with limited aging times. Aging was performed without applied voltage in an oven under nitrogen atmosphere to reduce any risk of chemical modifications. For each material, aging periods ranged from 5 days to 6 months. Five samples were taken out during 6 months to be investigated.

Differential scanning calorimetry (DSC) was employed to assess the enthalpy excess characterizing the physical aging for $\mathrm{C} 1$ and $\mathrm{C} 2$ samples during the laboratory accelerated ageing (Figure $2 \mathrm{a}$ and $2 \mathrm{~b}$ ). This analysis was carried out using a Perkin Elmer DSC 7. The DSC heating rate was $10^{\circ} \mathrm{C} \cdot \mathrm{min}^{-1}$ from 30 to $170^{\circ} \mathrm{C}$ for all samples containing about $10.0 \pm 0.5$ $\mathrm{mg}$ of polymer.

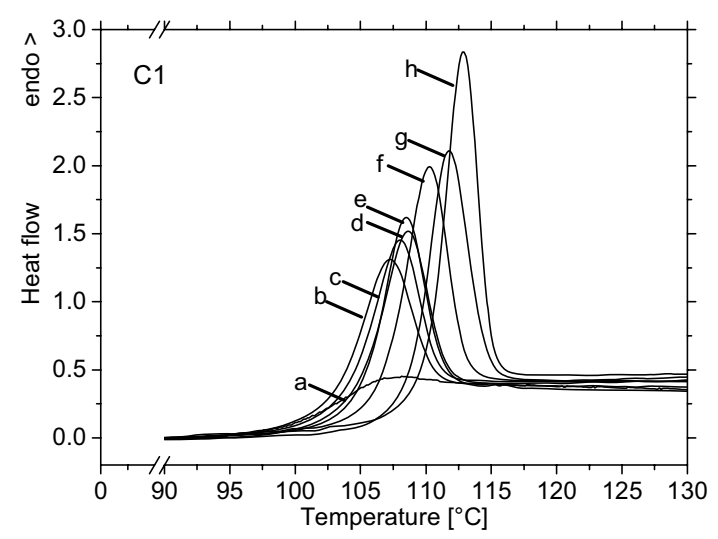

$(\alpha)$

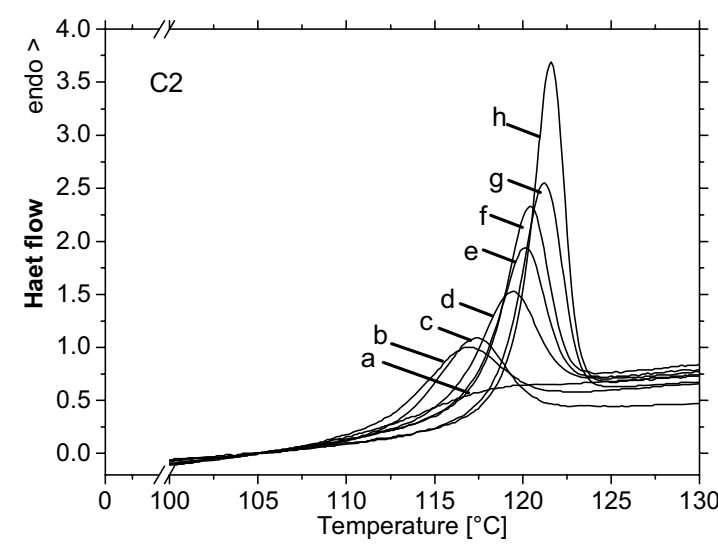

( $\beta)$

Figure 2. DSC Thermograms of as-received systems (a) and composites aged under laboratory conditions for (b) 9h, (c) 20h, (d) 5days, (e) 13 days, (f) 30 days, (g) 73 days, (h) 6 months - first ramp of temperature, composites $\mathrm{C} 1$ (2. $\square)$ and $\mathrm{C} 2(2 . \square)$

The exact polymer-filler weight ratios were corrected a posteriori thanks to Thermogravimetric Analysis (TGA) measurements performed on the samples used in DSC. The laboratory aging led to a set of samples with a large range of enthalpy excess, depending on the aging time (Figure 3) [24].

Several trials to directly reveal the increase in density due to physical aging of polymer were performed. The estimation of the actual density of the polymer remained however too sensitive to the amount of inorganic filler. The Figure 2 does however state by itself the physical aging process.

The $\mathrm{Tg}$ values measured on the second DSC scans (rejuvenated samples) remained constant for the entire set of aging times and for a given composite. It was thus concluded that no significant chemical modification of the polymer was imparted by the laboratory aging (see [24] for details) 

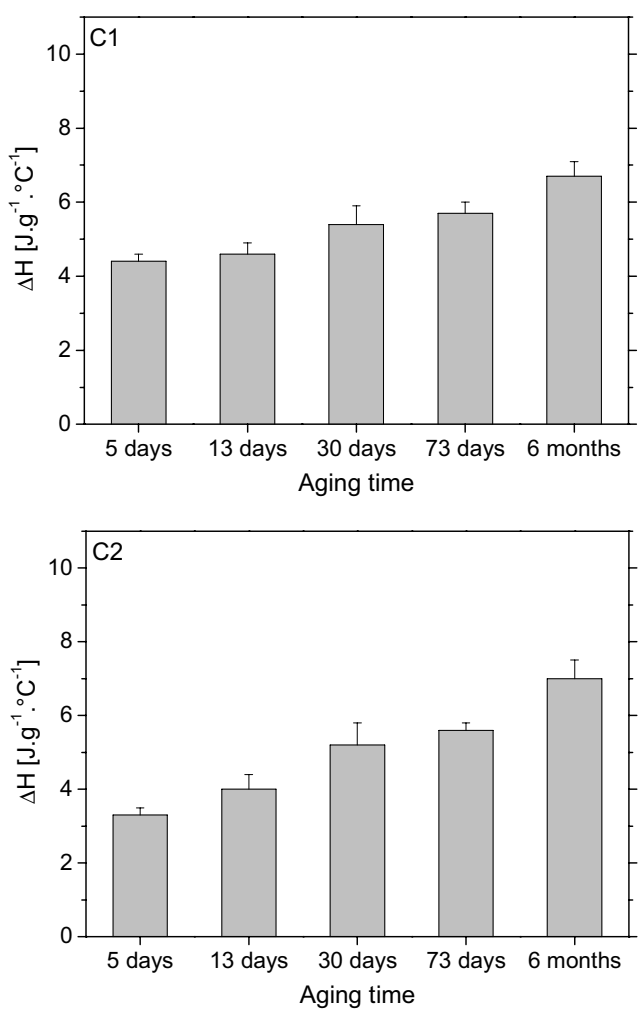

(b)

Figure 3. Characterization of the structural relaxation of the epoxy through DSC: enthalpy excess $\square \mathrm{H}$ as a function of aging time for the composites C1 (3a) and C2 (3b).

\subsection{BREAKDOWN VOLTAGE MEASUREMENTS}

The tests were performed at the ambient $\left(20^{\circ} \mathrm{C}\right)$ under ac voltage supplied by a $50 \mathrm{kV}, 50 \mathrm{~Hz}$ transformer. The breakdown voltages were determined as the average of four tests carried out in contact mode in ramp test. The specimen was immersed in silicon oil to prevent the surface discharges and flashovers.

The breakdown voltage measurements were performed under divergent and quasi-homogeneous fields, respectively in a point/plane (Figure 4a) and sphere/sphere (Figure $4 \mathrm{~b}$ ) electrode arrangements. The point electrodes were made of tungsten with a curvature radius of about $30 \mu \mathrm{m}$. The later was measured after each breakdown and corrected accordingly. The plane electrode was a flat copper disk with $77.5 \mathrm{~mm}$ in radius. Both spherical electrodes employed for experiments in the quasi homogenous configuration were made of stainless steel with a diameter of $15 \mathrm{~mm}$.

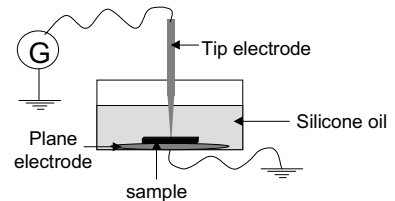

(a)

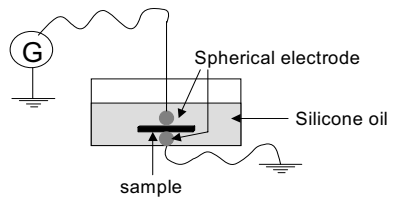

(b)
Figure 4. Test specimens used to measure the electrical breakdown voltage: (4a) point/plane electrodes and (4b) sphere/sphere electrodes.

Under divergent field (Figure 4a), the electrical field at the tip of the needle electrode is calculated using an hyperboloidal approximation [25].

$$
E=\frac{2 \times V}{r \times \ln \left(1+\frac{4 d}{r}\right)}
$$

Where $\mathrm{V}$ is the applied voltage, $\mathrm{d}$ is the electrode gap (equal to the sample width in contact mode) and $\mathrm{r}$ is the tip radius.

Under a quasi uniform field (Figure $4 \mathrm{~b}$ ), the electric field $\mathrm{E}$ associated to the electrical breakdown is calculated as follow:

$$
E=\beta \times E_{m}
$$

where $\mathrm{E}_{\mathrm{m}}=\mathrm{V} / \mathrm{d}$ is the measured field to breakdown and $\beta$ the non uniformity coefficient of the electric field; it depends on the geometry of the electrodes and it was very close to 1 in the present case. E mainly depends on the breakdown voltage and the electrode gap.

For the breakdown test, all samples were cut by an accurate cut off wheel to obtain a thickness, $d$, of $0.5 \mathrm{~mm} \pm 0.1$. They were then grounded and polished to obtain a mirror polished surface [26].

\subsection{SEM}

Observation of the breakdown tree paths were performed with a scanning electron microscope Stereoscan 440 LEICA. To obtain a good visualization of the treeing, a specific technique was performed. A straight line was first scored in one time on either sides of the perforation hole, purposely avoiding the vicinity of the hole, (Figure 5).

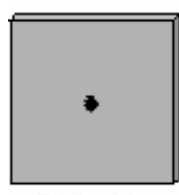

Dielectric breakdown

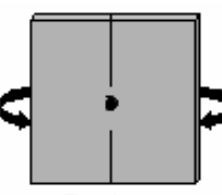

Rupture initiation

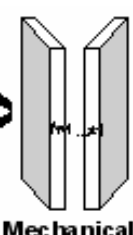

breaking

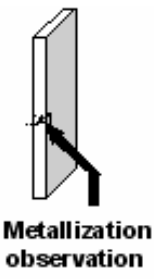

Figure 5. Sample preparation for treeing characterization with the SEM.

The samples were then broken away at room temperature using breaking pliers. Prior to characterization by SEM, the surfaces were eventually metallized with a thin gold layer (50 $\pm 20 \mathrm{~nm}$ ).

\section{RESULTS AND DISCUSSION}

The electrical breakdown field of the materials aged 20 years in service was first evaluated to quantify the influence of the global structural changes due to physical and chemical aging. 


\subsection{EFFECTS OF AGING IN ACTUAL SERVICE CONDITIONS ON THE ELECTRICAL BREAKDOWN}

Figure 6 shows a comparison of the field required for breakdown on as received composites (C1) and the aged counterpart $(\mathrm{C} 1 *)$. As expected the 20 years old material exhibited a significant decrease in the electrical breakdown field both in quasi homogeneous and divergent fields. This decrease was however remarkably low (about 10\%) taking into account the chemical degradations and structural modifications caused by 20 years aging in actual service conditions.
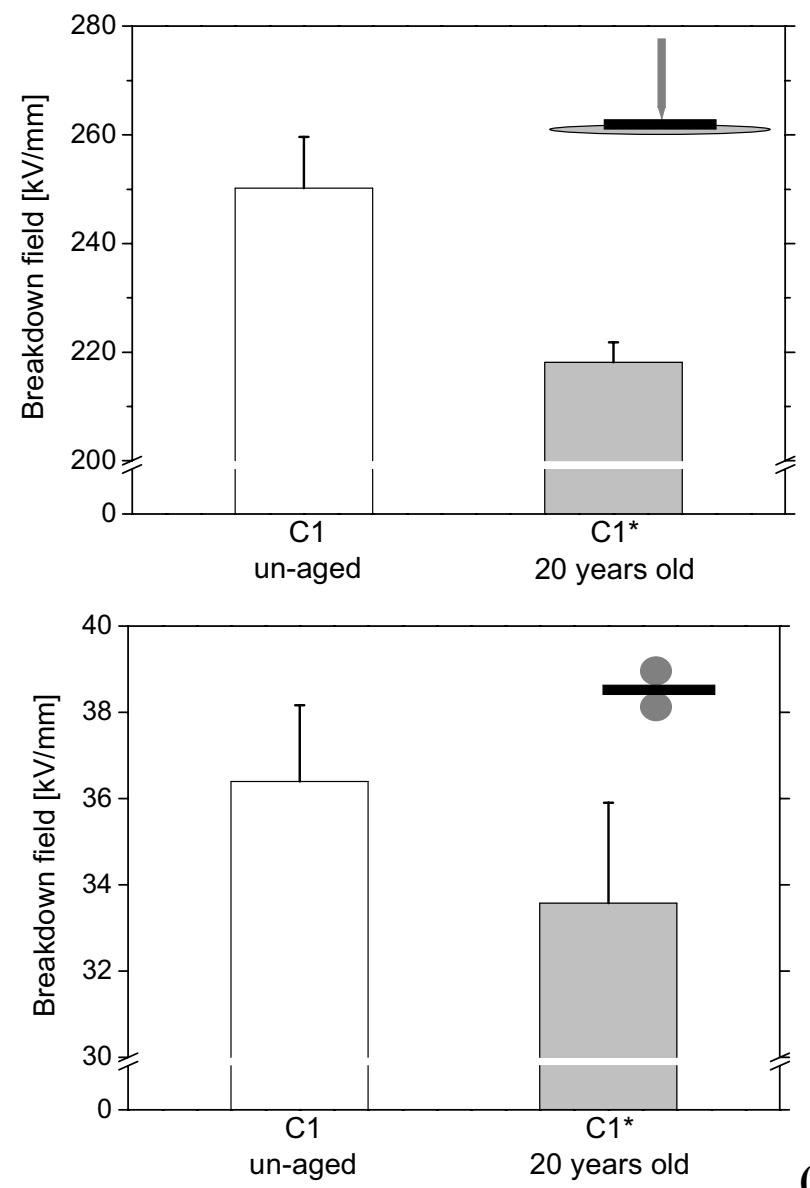

(a)

Figure 6. Comparative breakdown field for $\mathrm{C} 1$ and $\mathrm{C} 1$ * under divergent (a) and quasi-homogeneous (b) fields.

This result could however not alone permit the determination of the origin of this low decrease, i.e. to separate the relative contribution of the chemical modifications from that of the physical aging to the dielectric breakdown. In order to study the sole influence of physical aging on the dielectric properties under high field, laboratory structural aging tests were carried out.

\subsection{THE EFFECTS OF PHYSICAL AGING ON THE ELECTRIC BREAKDOWN}

Figures 7 and 8 show the evolution of the electric field required for the breakdown of the composites $\mathrm{C} 1$ and $\mathrm{C} 2$ as a function of enthalpy excess relative to laboratory aging time ranging from 5 days to 6 months. It was first noticed that the breakdown field monotonically increased with enthalpy excess $(\Delta \mathrm{H})$ both in divergent and quasi homogeneous configurations. Its variations obeyed an s shaped curve with $\Delta \mathrm{H}$ (as with the aging time, not shown). All the plots could indeed be divided into three zones: (i) initially the breakdown field seemed to not depend on the structural aging of the matrix, (ii) for an enthalpy excess ranging from 3.5 and $6 \mathrm{~J} \cdot \mathrm{g}^{-1} \cdot{ }^{\circ} \mathrm{C}^{-1}$ the field to breakdown improved largely with a relatively low variation of $\Delta \mathrm{H}$ and (iii) for the highest $\Delta \mathrm{H}$ (or aging times) a level off was evidenced.

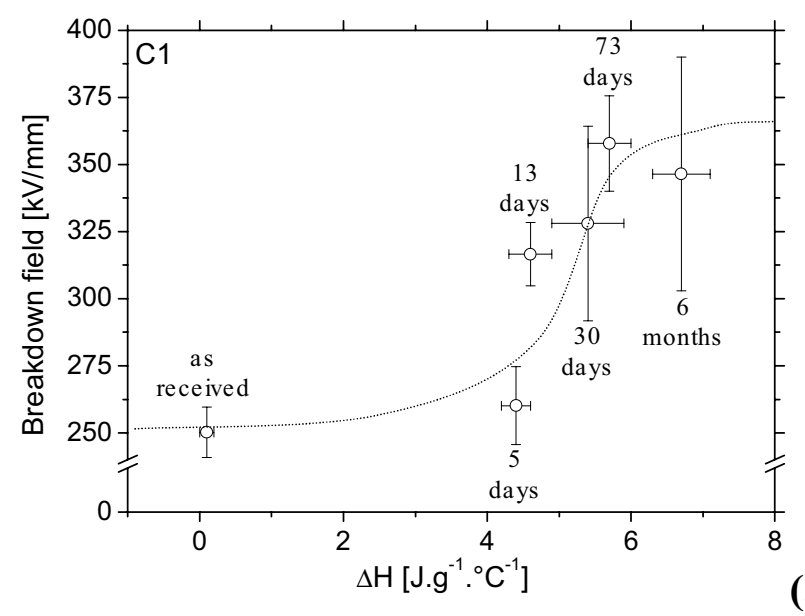

(a)

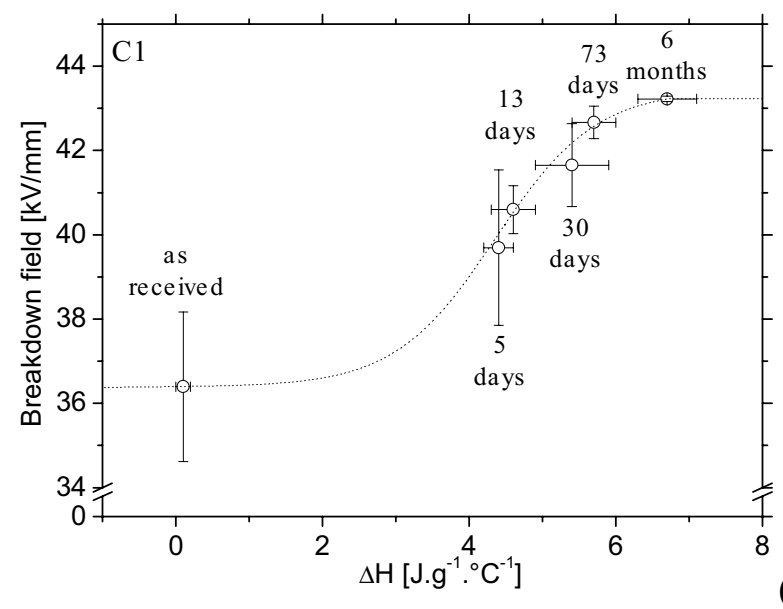

(b)

Figure 7. Electrical breakdown field as a function of enthalpy excess under divergent (a) and quasi homogeneous (b) field for the composite $\mathrm{C} 1$.

This behaviour was observed for both $\mathrm{C} 1$ and $\mathrm{C} 2$ in both divergent and quasi homogeneous field configurations. Qualitatively, this set of experiments showed that the matrix densification led to a non linear improvement of the electrical properties under high electric field. In agreement with Champion and Dodd [16], it can be proposed that the densification of the matrix changes the trap site depth and density. This mechanism can thus alter the high field conduction process, impedes the tree growth and thereby improve the breakdown field. 

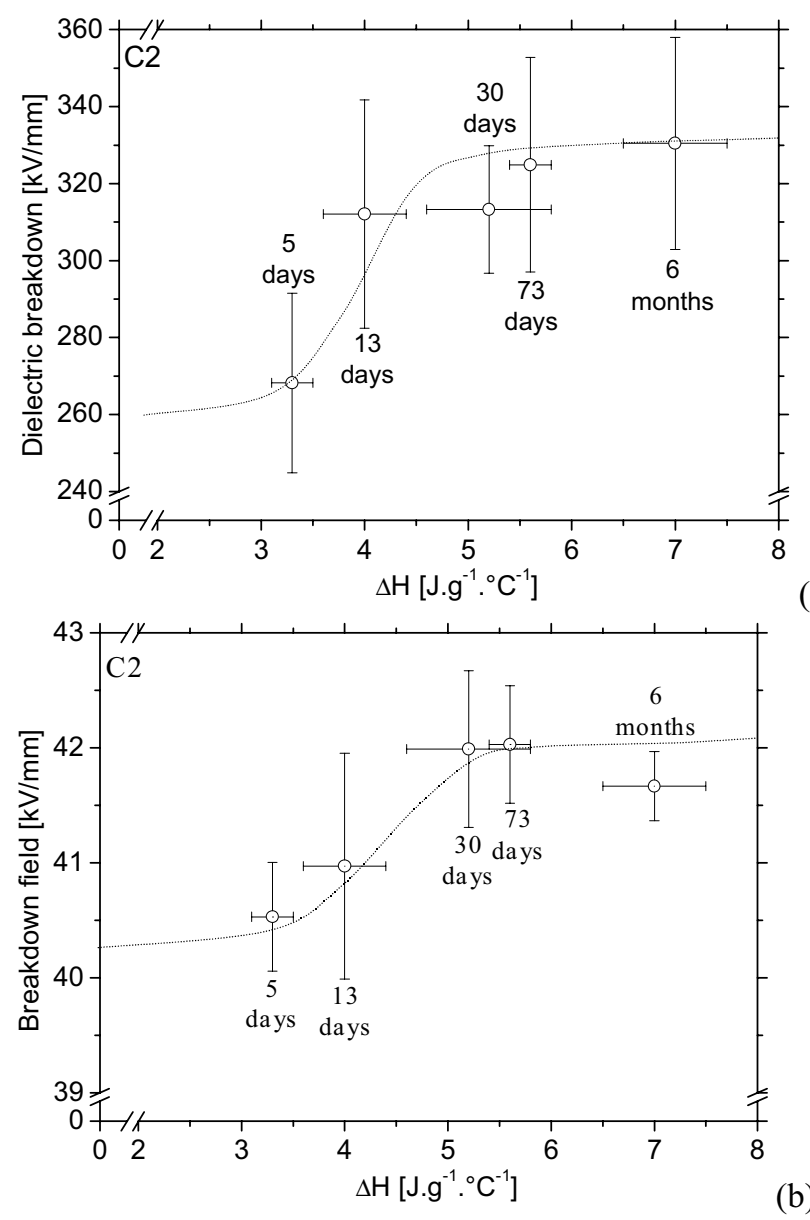

Figure 8. Electrical breakdown field as a function of enthalpy excess under divergent (a) and quasi homogeneous (b) field for the composite $\mathrm{C} 2$.

For comparison, the fields to breakdown were normalized to their initial values (i.e. for $\Delta \mathrm{H} \approx 0$ ) and represented in Figure 9. The analysis of the data revealed:

- two separate sets of data depending on the electrode geometry. The electric field configuration seemed thus to be the pertinent parameter separating small (quasi homogeneous field) and large (divergent field) sensitivity to physical aging.

- the two formulations exhibited rather minor differences, $\mathrm{C} 1$ was however overall more sensitive to the increase in $\Delta \mathrm{H}$ than $\mathrm{C} 2$.

In order to understand these results, SEM observations were carried out on the fracture surfaces after breakdown under divergent and quasi homogeneous fields. Figure 10 shows that under divergent field, the degradation was characterized by the formation of step arise trees, which were less than $3 \mu \mathrm{m}$ in length $[27,28]$. In contrast, under quasi homogeneous field, the electric field seemed to finally cause the formation of a $400 \mu \mathrm{m}$ in diameter crater without any remaining tree. These observations clearly revealed two distinct degradation mechanisms depending on the electrode geometry.

Based on the SEM observations, the differences in breakdown field vs. $\Delta \mathrm{H}$ (or aging time) revealed by the materials between the two electrode arrangements can be interpreted as follow:

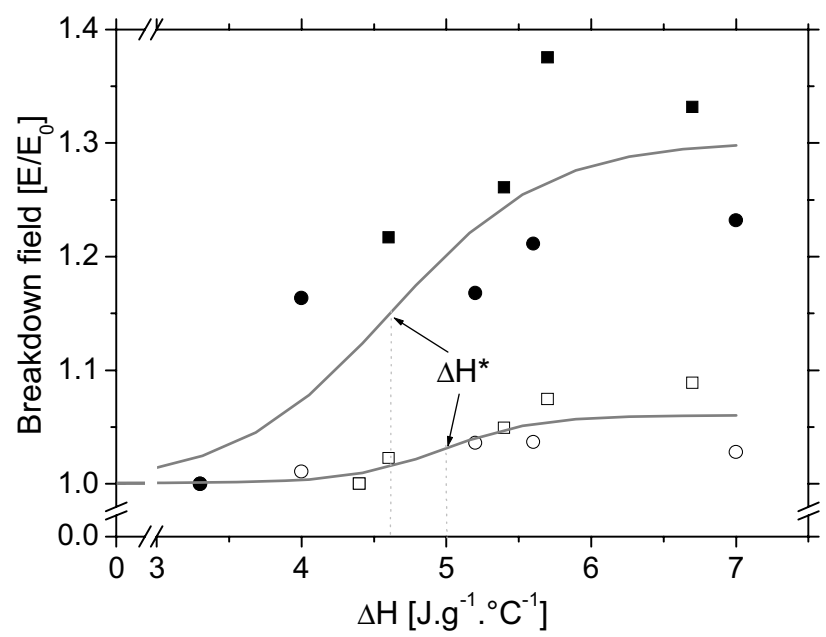

Figure 9. Normalized breakdown field as a function of enthalpy excess under divergent field for the composite $\mathrm{C} 1(\boldsymbol{\bullet})$ and $\mathrm{C} 2(\bullet)$ and under quasi homogeneous field for the composite $\mathrm{C} 1(\square)$ and $\mathrm{C} 2(\mathrm{O})$.
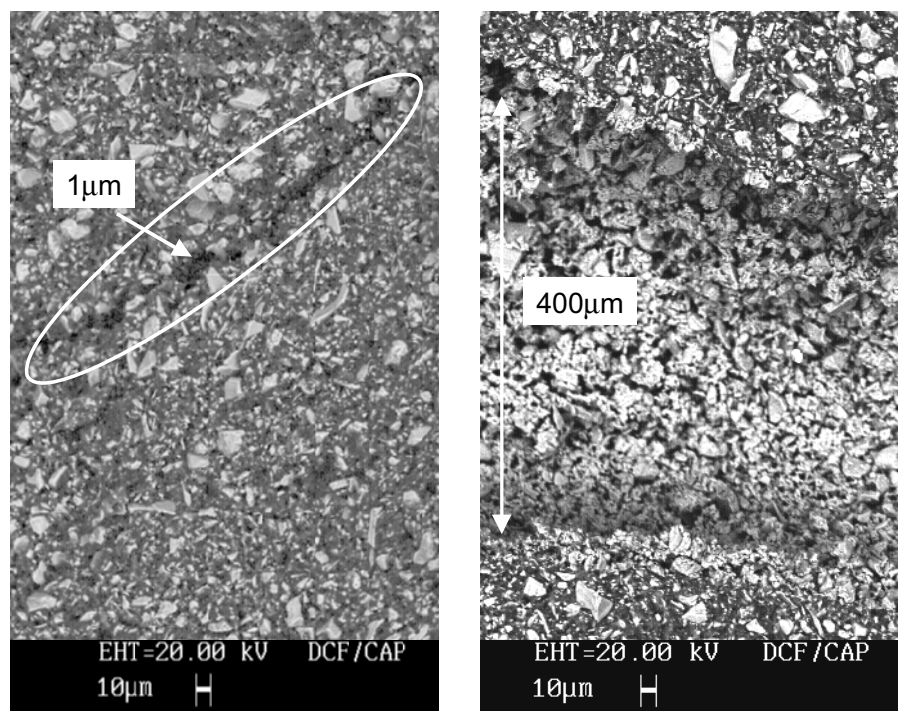

Figure 10. SEM images of the degraded areas for $\mathrm{C} 2$ composite under (a) divergent field and (b) quasi-homogeneous field

Under quasi homogeneous field, a global and broad breakdown cavity was observed. In this configuration the initial electrical field is macroscopically evenly distributed. The damage process could thus start with the help of the major flaws anywhere within the whole structure. Being the biggest heterogeneity, the filler is obviously expected to be the main origin for the field gradients. In particular, the biggest particles, those aligned to the electric field or with asperities primarily enhance the electric field close to their surfaces and the surrounding matrix can hence be defined as the "weakest link" in the composite. The presence of the particle is furthermore not altered by the structural modifications within the matrix. As a result, improving the properties of the polymeric host does not significantly change the main reason for breakdown. In summary, under quasi homogeneous field, the global nature of the electric field causes a high sensitivity to major flaws anywhere in the composite and the very local 
matrix densification only results in a small increase in the breakdown field.

Under divergent field the damage took the form of a filamentary like structure. Because of the large field enhancement associated to the tip electrode, the tree naturally starts in the vicinity of the tip electrode. The final tree structures showed that the field remained localized during the whole damage process and eventually lead to quasi one dimensional trees. This strongly cumulative process, spatially limited, prevented major flaws away from the trees controlling their spreading. The matrix densification could thus influence the tree propagation. In summary, under divergent field, the local nature of the field causes a low sensitivity to major flaws in the composite and the breakdown field is more sensitive to the matrix improvement.

\subsection{RESULTS OVERVIEW}

As already noticed, the breakdown field of $\mathrm{C} 1 *$ was only slightly lower $(10 \%)$ than that of the as received $\mathrm{C} 1$. It was however up to $40 \%$ lower than that of the $\mathrm{C} 1$ samples aged in laboratory, Figure 11.

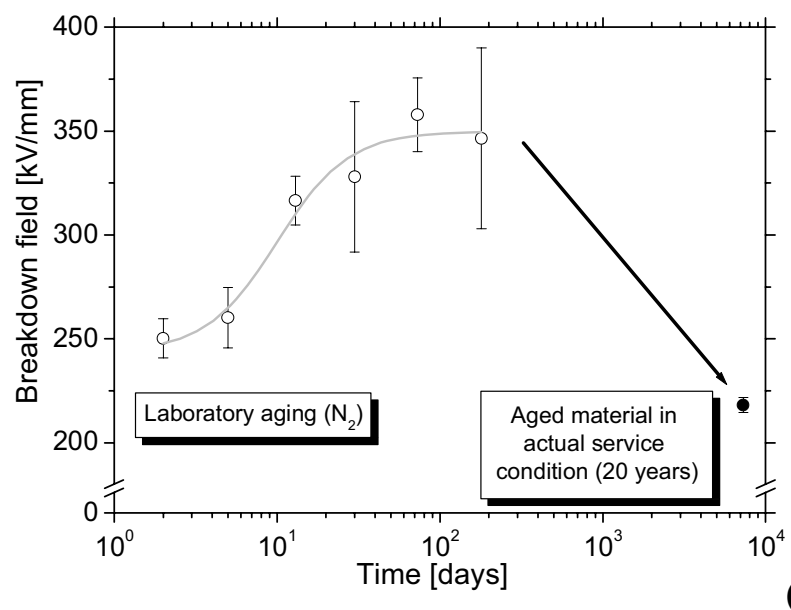

(a)

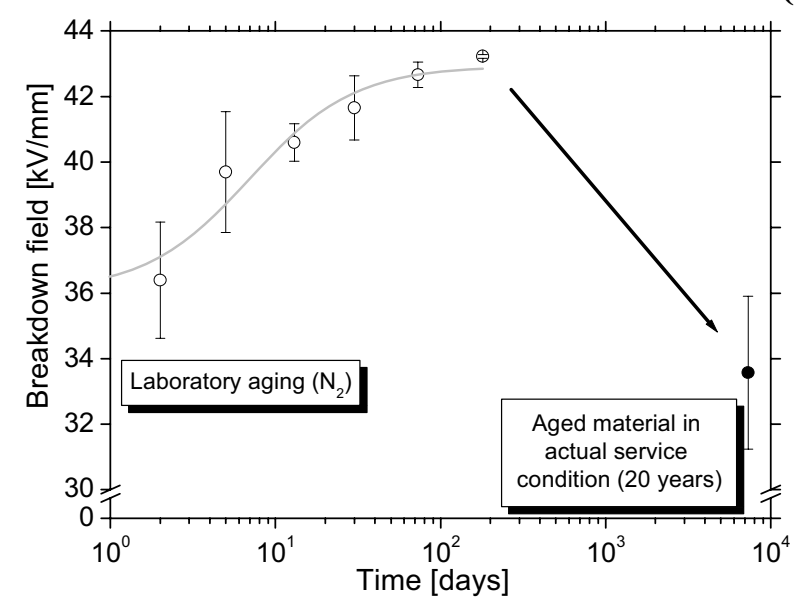

(b)

Figure 11. Electrical breakdown field as a function of aging time under divergent (a) and quasi homogeneous (b) field for the composites $\mathrm{C} 1(\mathrm{O})$ and $\mathrm{C} 1 *(\bullet)$.
This result indicates that two opposite effects might alter the dielectric breakdown of $\mathrm{C}^{*}$. On the one hand the dielectric breakdown is expected to strongly increase because of the structural recovery. On the other hand, the multiple stresses in actual conditions lead to chemical degradations. The subsequent formation of polar groups and free radical could be induced under electric field:

(i)a conduction current leading to overheating of the insulator by Joule effect that facilitates the dielectric breakdown by thermal effect

(ii) an increase in the amount of ionizing collisions generating a mechanism of electric breakdown by avalanche.

Both phenomena result in a significant decrease in breakdown field. It is thus proposed that the above mentioned opposite effects counterbalance each other, resulting in a low decrease of field associated with dielectric breakdown after a 20 years aging in actual service conditions with respect to as received materials $(\mathrm{t}=0)$.

Table 2. Characteristics of the s-shaped curves in Figure 9. The data was fitted to the Boltzmann function with the help of Origin ${ }^{\circledR}$ version 7.0 from OriginLab Corporation.

\begin{tabular}{ccc}
\cline { 2 - 3 } & $\begin{array}{c}\text { Tip/plane } \\
\text { Divergent field }\end{array}$ & $\begin{array}{c}\text { Sphere/sphere; Quasi } \\
\text { homogeneous field }\end{array}$ \\
\hline Amplitude & $30 \%$ & $6 \%$ \\
\hline $\begin{array}{c}\Delta \mathrm{H}^{*} \\
\text { characteristic }\end{array}$ & $4.6 \mathrm{~J} . \mathrm{g}^{-1} \cdot{ }^{\circ} \mathrm{C}^{-1}$ & $5.0 \mathrm{~J} . \mathrm{g}^{-1} .{ }^{\circ} \mathrm{C}^{-1}$ \\
\hline Width & $0.54 \mathrm{~J} . \mathrm{g}^{-1} \cdot{ }^{\circ} \mathrm{C}^{-1}$ & $0.32 \mathrm{~J} \cdot \mathrm{g}^{-1} \cdot{ }^{\circ} \mathrm{C}^{-1}$ \\
\hline
\end{tabular}

It is finally striking that the decrease in field to breakdown after 20 years of real service conditions does not appear to depend on the nature of the electrical field, Figure 11. The relative drop was indeed close to $10 \%$ both under divergent and quasi homogeneous fields for $\mathrm{C} 1$ * when compared to the unaged $\mathrm{C} 1$. It is however important to note that these two results apparently matched for very different reasons that do depend on the electrode configuration. A rough calculation was performed to investigate this interpretation, Table 3 . This analysis was performed using the experimental measurement describing the individual sensitivity of the field to breakdown to (i) physical aging (present paper) and (ii) degree of conversion [29]. In a first approximation, the chemical and physical influences were assumed to be independent.

- In the point plane configuration, the breakdown field strongly increases with the enthalpy excess, as presented in this work. The polymer network also presents, for the same reason, a high sensitivity to chemical degradations of the organic matrix [29]. Two strong effects thus oppose each other: a strong increase related to the physical aging and a strong decrease imparted by chemical degradations.

- In contrast, under quasi homogenous field, the dielectric strength is not much affected by either the physical aging (current paper) or chemical degradation [29]. Two effects, but with low amplitude thus oppose each other, basically leading to the same result as that of the divergent field configuration. 
The absolute values of the field to breakdown measured and calculated assuming independent contributions thus qualitatively confirmed the influence of the electrode configuration. Only for the tip plane configuration was the calculation not very satisfactory. This difference between calculated and measured data for the divergent field could be due to some degree of interdependence between the physical and chemical phenomena. It is however important to note that the sensitivity to chemical variation was only measured experimentally for a narrow range of extent of cure, $\alpha$ varying from 0.95 to 0.99 [29]. On this range of $\alpha$ a linear relationship was established between the field to breakdown and the extent of cure, thus obtaining a constant sensitivity. For the present calculation, it was assumed that the linear dependence could be extrapolated down to $\alpha=0.88$. This assumption should be first verified to conclude whether an interdependence between the chemical and physical structural changes alter the field to breakdown.

Table 3. Sum up of experimental and calculated data.

\begin{tabular}{|c|c|c|c|c|c|}
\hline & \multirow{3}{*}{$\begin{array}{c}\begin{array}{c}\text { Quasi } \\
\text { homogeneous }\end{array} \\
36\end{array}$} & \multirow{3}{*}{$\begin{array}{c}\text { Divergent } \\
250\end{array}$} \\
\hline & & & & & \\
\hline $\mathrm{C} 1$ & & (1) & $\begin{array}{l}\text { Experimental field breakdown of } \\
\mathrm{C} 1 \text { - "as received" }(\mathrm{kV} / \mathrm{mm})\end{array}$ & & \\
\hline \multirow{7}{*}{$\mathrm{C} 1 *$} & \multirow{2}{*}{$\begin{array}{c}\text { I. Chemical } \\
\text { effect }\end{array}$} & $(2)$ & $\alpha$ : conversion degree & \multicolumn{2}{|c|}{0.88} \\
\hline & & (3) & Field breakdown $(\mathrm{kV} / \mathrm{mm})$ & 29 & 130 \\
\hline & \multirow{2}{*}{$\begin{array}{l}\text { II. Physical } \\
\text { effect }\end{array}$} & (4) & $\Delta \mathrm{H}\left(\mathrm{J} \cdot \mathrm{g}^{-1} \cdot{ }^{\circ} \mathrm{C}^{-1}\right)$ & \multicolumn{2}{|c|}{5.2} \\
\hline & & (5) & Field breakdown (kV/mm) & 42 & 320 \\
\hline & \multirow{3}{*}{$\begin{array}{l}\text { III. Chemical } \\
\text { \& Physical } \\
\text { effects }\end{array}$} & (6) & Calculated Field breakdown (kV/mm) & 35 & 190 \\
\hline & & (7) & Calculated Field breakdown (kV/mm) & 34 & 170 \\
\hline & & (8) & Experimental field breakdown $(\mathrm{kV} / \mathrm{mm})$ & 34 & 220 \\
\hline
\end{tabular}

(1) Experimental field breakdown of $\mathrm{C} 1$ "as received" $(\alpha \approx 1$ and $\Delta \mathrm{H} \approx 0 \mathrm{~J} \cdot \mathrm{g}^{-1} \cdot{ }^{\circ} \mathrm{C}^{-1}$ )

\subsubsection{CALCULATED FIELD TO BREAKDOWN WITH ONLY CHEMICAL DEGRADATION}

Hypothesis: For this calculation (corresponding to $\mathrm{I}$ in the Table 3) $\Delta \mathrm{H}$ was assumed to be zero (no physical aging).

(2) $\alpha$ was approximated from the $\mathrm{Tg}$ of $\mathrm{C} 1 *$ using the Di Benedetto equation. This $\alpha$ value takes into consideration the chemical degradations of the $\mathrm{C} 1 *$ matrix [30]

(3) Field to breakdown of $\mathrm{C} 1 *\left(\alpha \approx 0.88\right.$ and $\left.\Delta \mathrm{H} \approx 0 \mathrm{~J} \cdot \mathrm{g}^{-1} \cdot{ }^{\circ} \mathrm{C}^{-1}\right)$ calculated from the sensitivity of dielectric breakdown field to $\alpha$ [29]

\subsubsection{CALCULATED FIELD TO BREAKDOWN WITH ONLY PHYSICAL AGING}

Hypothesis: For this calculation (corresponding to II in the Table 3) $\alpha$ was assumed to be one (no chemical degradation).

(4) Enthalpy excess associated with the physical aging of the composite $\mathrm{C} 1 *$ after 20 years in industrial aging [24]

(5) Field breakdown of $\mathrm{C}^{*}\left(\alpha \approx 1\right.$ and $\left.\Delta \mathrm{H} \approx 5.2 \mathrm{~J}^{*} \mathrm{~g}^{-1} \cdot{ }^{\circ} \mathrm{C}^{-1}\right)$ calculated with the curves of dielectric breakdown field versus $\Delta \mathrm{H}$ (Figure 7.a and Figure 7.b).This curve was used as an abacus.

\subsubsection{CALCULATED FIELD TO BREAKDOWN WITH BOTH CHEMICAL DEGRADATION AND PHYSICAL AGING}

Hypothesis: For these calculations (corresponding to III in the Table 3) the influence of chemical and physical changes were assumed to be independent.

(6) and (7) Field to breakdown of $\mathrm{C} 1 *(\alpha \approx 0.88$ and $\Delta \mathrm{H} \approx 5.2$ $\left.\mathrm{J} . \mathrm{g}^{-1} \cdot{ }^{\circ} \mathrm{C}^{-1}\right)$ calculated using respectively:

$$
\begin{aligned}
& \mathrm{E}(\alpha, \Delta \mathrm{H})=\mathrm{E}(\Delta \mathrm{H})+\frac{\partial \mathrm{E}}{\partial \alpha} \times \Delta \alpha \\
& \mathrm{E}(\alpha, \Delta \mathrm{H})=\mathrm{E}(\Delta \mathrm{H}) \times \frac{\mathrm{E}(\alpha)}{\mathrm{E}(\alpha=1)}
\end{aligned}
$$

(8) Experimental field breakdown of $\mathrm{C}^{*}{ }^{*}(\alpha \approx 0.88$ and $\Delta \mathrm{H}$ $\left.\approx 5.2 \mathrm{~J} \cdot \mathrm{g}^{-1}{ }^{\circ} \mathrm{C}^{-1}\right)$.

\section{Conclusion}

During 20 years in actual service conditions $\mathrm{C} 1$, an insulator based on epoxy reinforced by inorganic particles, underwent strong changes in its microstructure. DSC measurements indeed pointed out (i) a chemical degradation of the polymer network characterized by a shift of $\mathrm{Tg}$ towards lower temperatures and (ii) a structural recovery that was detected by the presence of an endothermic peak, characteristic of the so called physical aging. Considering these modifications, a large decrease in breakdown field was expected. A $10 \%$ decrease in breakdown field was however 
measured with respect to the as received sample, both in quasi homogeneous and divergent fields. In order to identify the mechanisms leading to this surprising relative stability and to evaluate separately the contribution of the structural recovery on the composite properties, laboratory physical aging tests were carried out in a controlled atmosphere (nitrogen). The laboratory aged materials showed that breakdown field actually increased with increasing enthalpy excess (associated with the structural aging). This phenomenon was attributed to the densification of the matrix which impedes tree growth by the reduction of the free volume. These results indicate that two opposite effects alter the dielectric breakdown of $\mathrm{C} 1$ * (i) the structural recovery which largely opposes dielectric breakdown and (ii) the multiple stresses in actual conditions which lead to chemical degradations and thereby lowers the field to breakdown. Both effects almost counterbalance each other after 20 years aging in actual service conditions.

It was also observed that the choice of the electrode geometry greatly altered the dielectric breakdown of these composites. It is proposed also here that in a quasi homogeneous field configuration the breakdown is mainly governed by the major flaws at the sample scale, namely the reinforcing particles. In other words measurements performed for instance in a sphere sphere configuration are not very sensitive to variations within the polymeric matrix. On the contrary, under divergent field, the field initially enhanced on the tip electrode remains localized at the tip of the growing tree during the whole breakdown process. As a result, the major flaws might not be reachable by the damage tree and an improvement in the matrix properties induces a strong increase of breakdown field. The influence of the electrode arrangement was confirmed by a semi quantitative analysis based on the hypothesis that the chemical and physical modifications acted independently.

\section{ACKNOWLEDGMENT}

Dr. Y. Kieffel from AREVA T\&D is gratefully acknowledged for his reading of the manuscript and fruitful comments. The authors would like to thank O. Romeyer of the Savoie University for his valuable help in getting the SEM micrographs, F. Chappuis of the CEGELY - Ecole Centrale de Lyon for the preparation of the electrodes. The authors are grateful to the region Rhône Alpes for financial support throughout its 'Thématiques Prioritaires' grants. The financial support from AREVA-T\&D was appreciated.

\section{REFERENCES}

[1] L.A. Dissado and J.C. Fothergill, "Electrical Degradation and Breakdown in Polymers", in IEE Materials and devices, Vol. 9, ed. Morgan, Parkman, and Overshott, London, 1992.

[2] J.J. O'Dwyer, The Theory of Electrical Conduction and Breakdown of Solids, Clarendon Press, Oxford, 1973.

[3] M. Fröhlich, Theory of Dielectrics, Oxford University Press, 1949.

[4] J.K. Nelson, "Breakdown Strength of Solids", in Engineering Dielectrics, Vol. IIA, ASTM Stol, Bartnikas/Eichhorn, Editors, pp. 445-520, 1983.

[5] J.J. O'Dwyer and B.L. Beers, Thermal breakdown of dielectrics, Conf. Electr. Insul. Dielectr. Phenomena, pp.193-198, 1981.
[6] K.H. Stark and G.C. Garton, "Electric strength of irradiated polyethylene", Nature, Vol. 176, pp. 1225-1226, 1955.

[7] E. Hallen, Electromagnetic Theory, Chapman and Hall, pp. 35-73, 1962.

[8] C. Brosseau and A. Beroual, "Computational electromagnetics and the rational design of new dielectric heterostructures", Progress in Materials Science, Vol. 48, pp. 373-456, 2003.

[9] C. Hudon, R. Bartnikas and M.R. Wertheimer, "Effect of physicochemical degradation of epoxy resin on patial discharge behavior", IEEE Trans. Electr. Insul., Vol. 2, pp.1083-1094, 1995.

[10]V. Ollier-Dureault and B. Gosse, "Photo-oxidation and Electrical Aging of Anhydride-cured Epoxy Resins", IEEE Trans. Dielectr. Electr. Insul., Vol. 5,pp. 935-943, 1998.

[11]V. Ollier-Dureault and B. Gosse, "Photooxidation of anhydride-cured epoxies: FTIR study of the modifications of the chemical structure", J. Appl. Polymer Sci., Vol. 70, pp. 1221-1237, 1998.

[12]D.M. Hepburn, I.J. Kemp, A.J. Shields and J. Cooper "Degradation of epoxy resin by partial discharges", IEE Proc. -Sci. Meas. Technol., Vol. 147, pp. 97-104, 2000.

[13]D.M. Hepburn, I.J. Kemp and J.M. Cooper, "Degradation of filled epoxy resin surfaces", Polymer Degradation and Stability, Vol. 70,pp. 245-251, 2000 .

[14]M. Beyer, "Electrical and Dielectric Behaviour of Cast Epoxy Resins", Institute of Electric Power Systems (Schering-Institute), Hannover University, Vol. 1, 1991.

[15]R. Schifani, R. Candela and P. Romano, "On PD mechanisms at high temperature in voids included in an epoxy resin", IEEE Trans. Dielectr. Electr. Insulat., Vol. 8, pp. 589-597, 2001.

[16] J.V. Champion and S.J. Dodd, "The effect of voltage and material age on the electrical tree growth and breakdown characteristics of epoxy resins", J. Phys. D. Appl. Phys., Vol. 28, pp. 398-407, 1995.

[17]J.V. Champion and S.J. Dodd, "Systematic and reproducible partial discharge patterns during electrical tree growth in an epoxy resin", J. Phys. D Appl. Phys., Vol. 29, pp. 862-868, 1996.

[18]J.V. Champion, S.J. Dodd and J.M. Alison, "The correlation between the partial discharge behaviour and the spatial and temporal development of electrical trees grown in an epoxy resin", J. Phys. D Appl. Phys., Vol. 29, pp. 2689-2695, 1996.

[19]G. Löffelmacher, Uber physikalisch-chemischen Vorgängee bei der Ausbildung van Entladungskanälen in Polyethylen und Epoxydharz im inhomogenen Wechelfeld, Diss. TU Hannover 1976.

[20]T. Las, "Measurement of solid dielectric surface temperature increment arising from partial discharge activity", IEEE Intern. Sympos. Electr. Insul., Anaheim USA, 2000.

[21] S. Montserrat, "Physical aging studies in epoxy resins. I. Kinetics of the enthalpy relaxation process in a fully cured epoxy resin", J. Polymer Sci Part B: Polymer Phys., Vol. 32, pp. 509-522, 1994.

[22]M. Beyer, W. Boeck, K. Möller and W. Zaengl, "Hochspannungstechnik", Springler-Verlag, Berlin, p. 167, 1986.

[23]D.W. Auckland, J.M. Cooper and B.R. Varlow, "Factors affecting electrical tree testing", IEE Proc.-A, Vol. 139, pp. 9-13, 1992.

[24]L. Vouyovitch, L. Flandin, J-L. Bessede, and N.D. Albérola "Evolutions of microstructure and dielectric behavior of epoxy based insulatorinsulator composites over long periods of time", J. Appl. Polymer Sci., in press.

[25] J.H. Mason, "Breakdown of solid dielectrics in divergent fields", Proc. IEE, Vol. 102, pp. 254-263, 1955.

[26]L. Vouyovitch, Relation Entre Architecture et Rupture Diélectrique de Composites Isolant-isolant: Approches Expérimentales et Théorique", Ph.D. Thesis, LMOPS, Savoie University, France, 2004.

[27]A.L. Barclay, P J Sweeney, L A Dissado and G C Stevens "Stochastic modelling of electrical treeing: fractal and statistical characteristics", J. Phys. D Appl. Phys., Vol. 23, pp. 1536-1545, 1990.

[28]P.J.J. Sweeney, L.A. Dissado and J.M. Cooper, "Simulation of the effect of barriers upon electrical tree propagation", J. Phys. D Appl. Phys., Vol. 25, pp. 113-119, 1992.

[29]L. Flandin, L Vouyovitch, A Beroual, J-L Bessede and N D Alberola "Influences of degree of curing and presence of inorganic fillers on the ultimate electrical properties of epoxy-based composites: experiment and simulation", J. Phys. D: App. Phys., Vol. 38 , pp.144-155, 2005.

[30]L. Vouyovitch, L. Flandin, G. Merle, J-L. Bessede and N.D. Albérola, "Influence of the processing on the completion of curing in epoxy-based composites”, J. Appl. Polymer Sci., Vol. 96, pp.1368-1376, 2005. 


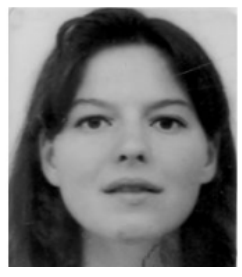

Dr. Laëtitia Vouyovitch Van Schoors was born in Lyon, France in 1974. She received the M.Sc. degree from the University of Savoie, France in 2000 and the Ph.D. degree from the University of Savoie (Laboratoire des Matériaux Organiques à Propriétés Spécifiques), Bourget du Lac, France in 2004. She is now researcher in the Division for Material Physicochemistry (PCM) in the LCPC (Laboratoire Central des Ponts et Chaussées), Paris, France. This division has widened its knowledge base on the characteristics of civil engineering materials while at the same time researching innovative products. More precisely, she works on the durability of the geosynthetics used in engineering structures.

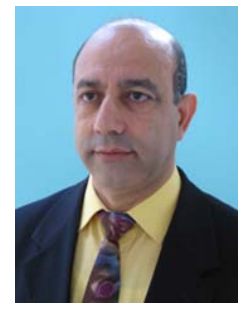

Prof. Abderrahmane Beroual (M'92) was born on 30 October 1951. He received the Dipl. Ing. and Ph.D. degrees in electrical engineering, respectively in 1976 from the Ecole Nationale Polytechnique of Algiers, Algeria and in 1979 from the Technical University of Wroclaw, Poland. In 1987, he obtained the Doctorat d'Etat ès Sciences Physiques degree from the Institut National Polytechnique of Grenoble, France. In 1980, he joined the Department of Electrical Engineering at the Ecole Nationale Polytechnique of Algiers. From 1983 to 1987, he was a researcher at the Laboratoire d'Electrostatique et de Matériaux Diélectriques (LEMD) - CNRS of Grenoble, France and associate professor at the Joseph Fourier University of Grenoble. He received the title of professor at the Ecole Nationale Polytechnique of Algiers in 1987. In 1989, he joined the Ecole Centrale de Lyon, France where he is presently professor and the head of the Dielectric Materials and High Voltage team at the Centre de Génie Electrique de Lyon (CEGELY) - CNRS as well as the Responsible of the Master Research Program in Electrical Engineering. $\mathrm{He}$ is responsible of numerous research projects. His main research interests include high voltage insulating, dielectric materials, long air discharge and lightning, modelling of discharges and composites. He is author/co-author of more than 220 papers and four patents. He supervised about $30 \mathrm{PhD}$ theses. He was the leadership of the International Study Group on Streamer Propagation in Liquids of the IEEE - DEIS (1994 - 1998). He is on the International Advisory Committees of the International Conference on Dielectric Liquids and the International Conference on Advances in Processing, Testing and Application of Dielectric Materials.

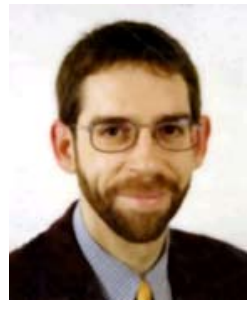

Dr. Jean-Luc Bessède (M'96-SM'05) has an Engineer degree (MS) from the National School of Ceramic Engineering from Limoges (France) and a Ph.D. degree in material science from the National Institute for Applied Science of Lyon (France). He has worked for four years as research engineer in material science first in the Arsenal of Tarbes (France) then by BSN Emballage in Villeurbanne (France). He joined the Switchgear Research Center of Alstom
T\&D (ARC) (now AREVA T\&D) in 1990 as a research engineer on insulating materials. Since 1991, he has the responsibility of Research \& Development on materials for high voltage circuit breakers and transformers. He has been Environment Manager of the Switchgear Research Center for three years. He is also in charge of the co-ordination of Ecodesign activities within AREVA T\&D and is president of the WG Environment of GIMELEC. Jean-Luc has already published more than 40 papers either in the field of material science \& engineering and eco-design. He participated in a dozen of international Standards and received more than 10 patents. He Chaired ICCE 2000, and the SEE Workshop on Corrosion of Sub-station equipment, Overhead lines and cables in 2001. He is a member of several technical committees as the conferences INSUCON 2002 and INSUCON 2006.

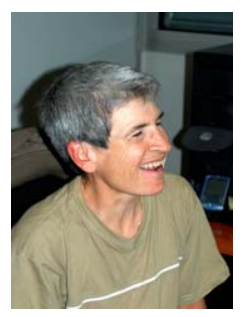

Prof. N.D. Alberola has a degree in material engineering, INSA, Lyon, France in 1976, a Ph.D. degree, Université Claude Bernard, Lyon, Francein 1982, a MD degree, Faculté de Médecine de Lyon I, France, 1983, Docteur ès Sciences Physiques, INSA, Lyon, France, 1989. Biomed. Engineer from 1976 to 82 in the Louis Pradel Cardiology Hospital, Lyon, France. Clinician Assistant Professor from 1982 to 1985 in the Louis Pradel Cardiology Hospital, Lyon, France. Assistant Professor from 1985 to 1990 in the Laboratoire de Tribologie, Ecole Centrale de Lyon, France. Professor Chemistry from 1990- 1993, Head of Composite Materials Dpt, Engineering School (ESIGEC), Université de Savoie, France. Head of Laboratoire Matériaux Polymères et Composites from 1993 to 1999 Université de Savoie, France. Since 1999Assistant Head of Laboratoire Matériaux Organiques à Propriétés Spécifiques, CNRS, Université de Savoie. Head of Institute of Technology, Université de Savoie, France since 2000. Contributed to more than 200 papers. Prof. Albérola supervised about $30 \mathrm{Ph} . \mathrm{D}$. students. Achievements include patents and collaborations with various companies.

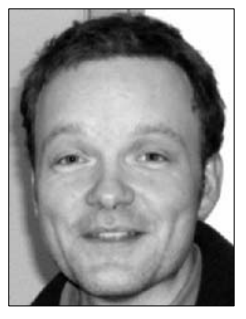

Dr. Lionel Flandin was born in July 1970. He obtained a Masters degree (1992, Physics) and a Ph.D. degree (material science, 1998) in Grenoble France. Lionel worked as Research Associate in the CWRU (Cleveland Ohio, USA) from 02/98 to 08/99 and spent a year in the Rhodia research center in Paris. He joined the LMOPS in 2000 as assistant Professor. His research activities concern the structure-property-processing relationships of polymers and composites and more specifically the hierarchical relationships between structures and electrical and dielectric properties. His activities concern both the experimental characterizations and the development of numerical codes to understand the structure/properties relationships. He co-authored about 40 peer-reviewed publications papers and 7 patents. $\mathrm{He}$ is a member main technical committee for INSUCON 2006 and a member of the Editorial Board for the Journal of Applied Polymer Science. 